\title{
Stability Analysis and Treatment Measure of the Mining Stope Slope
}

\author{
Qinglan Qi \\ Shijiazhuang Tiedao University \\ Shijiazhuang, China \\ e-mail: qqinglan@sina.com
}

\author{
Shaoxiong Zhang \\ Shijiazhuang Tiedao University \\ Shijiazhuang, China \\ e-mail: shaoxiong-zhang@163.com
}

\author{
Yanchao Xie \\ Hebei Dubang Petro-Chemical Engineering Design \\ Co.Ltd \\ Shijiazhuang, China \\ e-mail: 407189778@qq.com
}

\begin{abstract}
This Based on the stope in HeBei province, the sliding failure mode and treatment measure after the excavation of the stope is discussed. The RMR methods and the GSI methods are both used to estimate the mechanical parameters of the rock mass, and the smaller parameters are selected for the stability calculation. The numerical simulation of the slope excavation by finite element is carried out, and the development of the displacement and plastic zone during the excavation are analyzed. Furthermore, the stability analysis of the excavated slope is carried out, and the results showed the safety factors cannot meet the standard requirement. Then the bolt support are used to reinforce the excavated slope, and the calculation results show that the safety factors of the reinforced slope can meet the requirement of the relative standards.
\end{abstract}

Keywords- mine stope; stability of the slope; plastic zone; bolt support

\section{INTRODUCTION}

Stability analysis of rock slope is a systematic engineering, including influence factors of slope instability, stability prediction, the value of shear strength parameters of rock, stability analys is and prevention measures, et $\mathrm{al}^{[1-5]}$ The individual qualitative analys is or quantitative analys is cannot completely reflect slope status. This paper takes the actual project as an example, carried out preliminary study from field measurement about main influencing factors of instability, qualitative judgement of instability, laboratory test and the occurrence of structural plane, the value of shear strength parameters of rock and finite element analysis, in detail introduced the process of stability analysis, using energy method for stability analysis of slope that divided sliding soil into multiple-block mode, then based on Mohr-Coulomb failure criterion and associated flow rule, structure a coordinated displacement field, and according to principle of virtual work, obtained upper limit of slope safety factor, and gave governance suggestions.

The stope located at the east side of Taihang Montain in the west of HeBei province. Three-class structural unit is Taihang Montain arch fault bundle. Four-class structural unit is Zanhuang fornix fault bundle. Earthquake influence mainly comes from the seismic belt of the eastern HeBei plane and the western JinHuo, consided as distant earthquake, tectonic stability in this area. According to" Code for Seis mic Design of Buildings"(GB50011-2001), the seismic fortification intensity in reservoir 6 degrees, design basic earthquake acceleration value $0.05 \mathrm{~g}$, the design earthquake groups for the first group. Slope before excavation was shown in Fig. 1, slope after excavation was shown in Fig. 2. This paper mainly discuss possible sliding failure mode and controlmeasures.

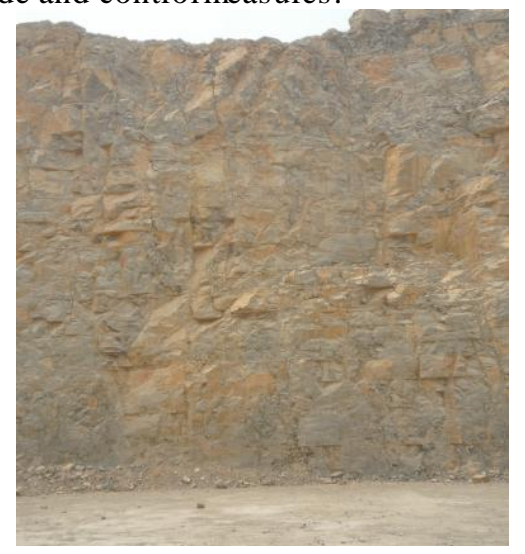

Figure 1. Stope slope before excavation

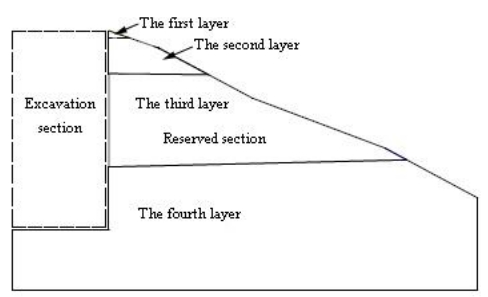

Figure 2. Excavation form schematic diagram 


\section{VALUE OF MECHANICAL PARAMETERS}

The methods for determining the mechanical parameters of rock slope include in-situ test method, inverse analysis method, numerical calculation method and empirical reduction method, rock mechanics classification method (RMR), rock mass geological strength index GSI estimation method, etc. This paper used the RMR methods and the GSI methods to estimate the mechanical parameters of the rock mass, and the smaller parameters are selected for the stability calculation.

\section{A. RMR Value}

RMR based on the five factors to comprehensively evaluate of rock mass strength: uniaxial compressive strength of rock, discontinuity spacing, rock quality index RQD, discontinuous surface conditions and groundwater conditions.

It's divided into four parts according to the distribution of the structural plane of rock mass as shown in Fig. 2. From the field survey and laboratory test, the RMR score of each part was shown in Table I . After RMR score, the total score of each rock strata and shear strength parameters were shown in Table II.

TABLE I. RMR SCORE OF EACH ROCK STRATUM

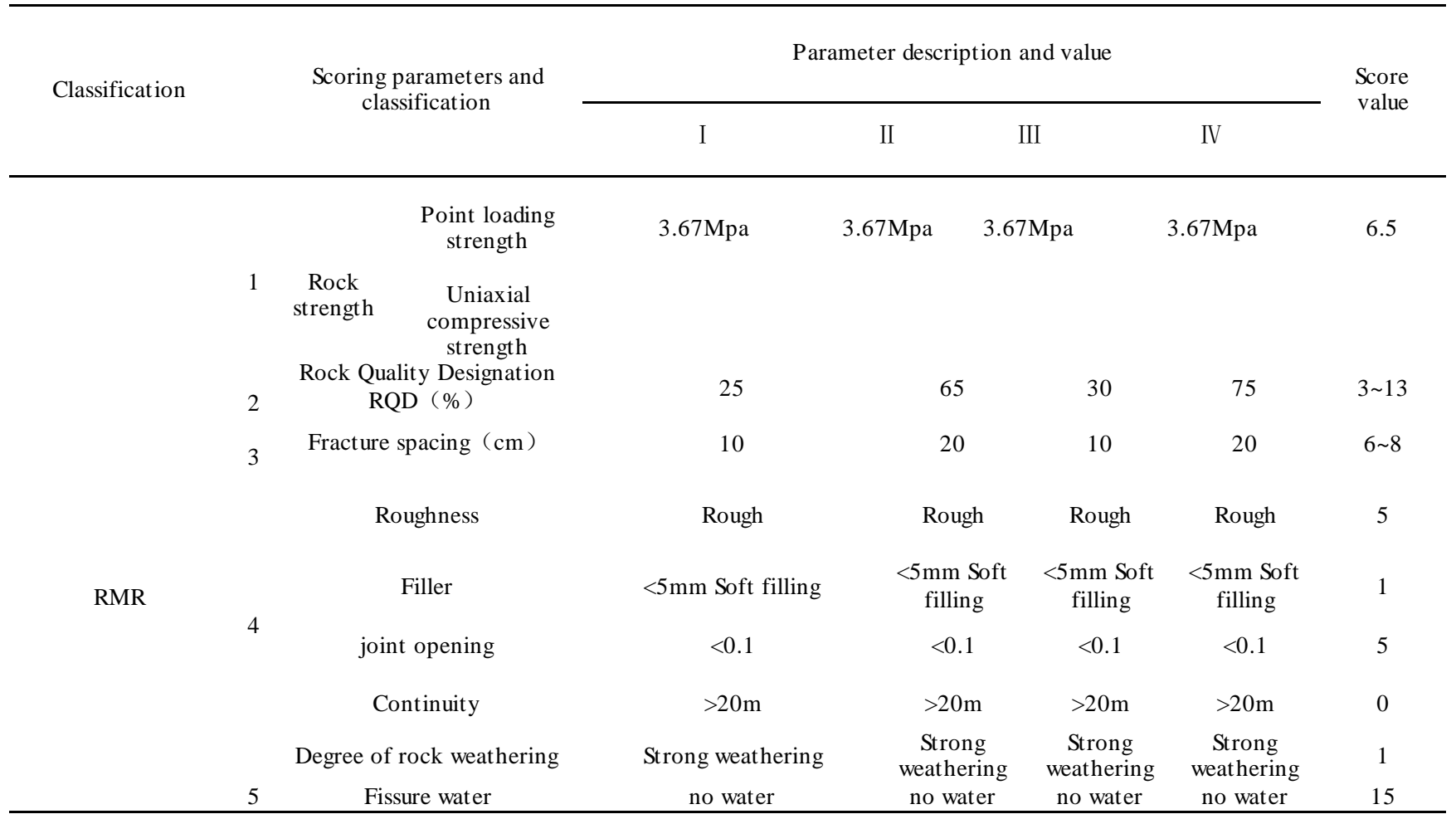

TABLE II. RMR SCORE VALUE OF EACH ROCK STRATUM

\begin{tabular}{ccccc}
\hline Position & I & II & III & IV \\
\hline RMR total score & 42.5 & 52.5 & 43.5 & 54.5 \\
\hline Normal cohesive force $(\mathrm{Kpa})$ & 212.5 & 262.5 & 217.5 & 272.5 \\
\hline Normal friction angle $\left({ }^{\circ}\right)$ & 26.25 & 31.25 & 26.75 & 32.25 \\
\hline
\end{tabular}

\section{B. GSI Value}

GSI method is divided into two steps, the first step is to evaluate the quality of rock mass, according to the empirical formula, the second step is to determine the shear strength parameters $c$ and $\varphi$ of the rock mass, the rock uniaxial compressive strength $\sigma_{j}$, elastic modulus $E_{j}$, GSI value of each rock layer and its shear strength parameters are shown in Table III. 
TABLE III. GSI VALUES OF EACH ROCK STRATUM AND THEIR SHEAR STRENGTH PARAMETERS

\begin{tabular}{|c|c|c|c|c|}
\hline Classification index & $\mathrm{I}$ & II & III & IV \\
\hline JW & $1.3 \sim 1.5$ & $1.0 \sim 1.2$ & $1.0 \sim 1.3$ & $1.1 \sim 1.3$ \\
\hline JS & $1.5 \sim 2$ & $1.5 \sim 2$ & $1.5 \sim 2$ & $1.5 \sim 2$ \\
\hline JA & $3 \sim 4$ & $3 \sim 4$ & $3 \sim 4$ & $3 \sim 4$ \\
\hline $\mathrm{JC}$ & $0.4875 \sim 1$ & $0.25 \sim 0.8$ & $0.375 \sim 0.87$ & $0.4125 \sim 0.87$ \\
\hline Joint spacing/cm & 10 & 20 & 10 & 20 \\
\hline GIS values & $30 \sim 40$ & $32 \sim 42$ & $27 \sim 37$ & $35 \sim 43$ \\
\hline $\begin{array}{l}\text { GIS values considered } \\
\text { Blasting disturbance }\end{array}$ & $40 \sim 50$ & $42 \sim 52$ & $37 \sim 47$ & $45 \sim 53$ \\
\hline $\mathrm{s}$ & $0.00127 \sim 0.00386$ & $0.00158 \sim 0.00482$ & $0.000912 \sim 0.00277$ & $0.0022 \sim 0.0054$ \\
\hline $\mathrm{mi}$ & 10 & 10 & 10 & 10 \\
\hline $\mathrm{mb}$ & $1.173 \sim 1.6767$ & $1.26 \sim 1.800$ & $1.053 \sim 1.506$ & $1.402 \sim 1.866$ \\
\hline A & $0.476 \sim 0.547$ & $0.4897 \sim 0.5625$ & $0.456 \sim 0.524$ & $0.5125 \sim 0.570$ \\
\hline B & $0.882 \sim 0.9201$ & $0.8894 \sim 0.9291$ & $0.872 \sim 0.907$ & $0.9 \sim 0.9338$ \\
\hline $\mathrm{Cm} / \mathrm{MPa}$ & $0.105 \sim 0.187$ & $0.118 \sim 0.210$ & $0.0889 \sim 0.158$ & $0.140 \sim 0.222$ \\
\hline
\end{tabular}

Through the above analysis, the difference of the friction angle based on RMR and GSI is not significant, the cohesion value of the former is greater than that of the latter.

\section{FINITE ELEMENT ANALYSIS OF SLOPE AFTER EXCAVATION}

As a two-dimensional plane strain finite element model, calculation simulate the geological conditions of calculation section as possible in order to meet the objective reality. The numerical model includes the main joints of rock mass and the simulation of the geological environment in which they are located. Based on the Mohr-Coulumb criterion, ABAQUS software is used to simulate the process of slope excavation, and the development of the displacement and plastic zone during the excavation are calculated.

As is shown in Fig. 3 and Fig. 4, the maximum displacement occurs in the red area near the excavation surface, about $15 \mathrm{~cm}$, the displacement value in the mountain green area is about $2 \mathrm{~cm}$, which is easy to move along the sliding zone.

Plastic zone represents permanent deformation, the mountain have not plastic zone before excavation under the surrounding constraints. After excavation, constraint is released, mountain free deformation, plastic zone as shown in Fig. 5. In the toe of the mountain, plastic zone is most obvious.

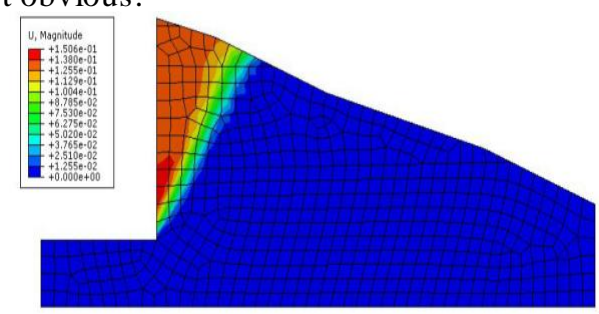

Figure 3. Displacement diagram of A-A' profile of excavation

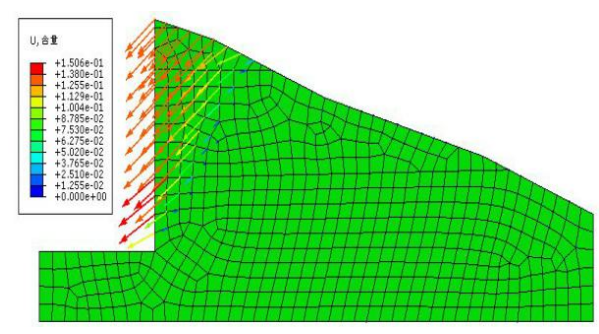

Figure 4. Ddirection of A-A' profile of excavation

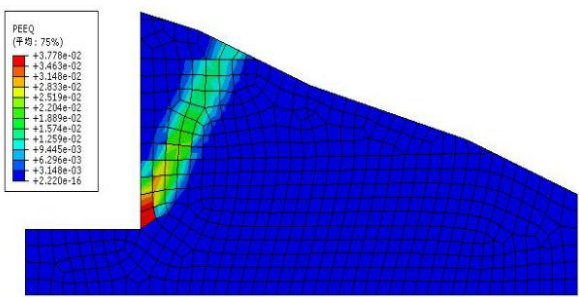

Figure 5. Plastic zone of A-A'profile of excavation

\section{ST ABILITY ANALYSIS OF SLOPE}

Stability analysis of slope based on stiffness limit equilibrium method. Calculation conditions includes normal condition, normal plus rainfall, normal plus earthquake, normal plus rainfall plus earthquake. By setting pore pressure coefficient to simulate rainfall influence to anti-sliding force, empirical value is $0.1 \sim 0.15,0.15$ is taken. This area belongs to 4 degree seismic region. Over safety concerns, this project imposes a horizontal seismic force to carry out pseudostatic method, takes horizontal seismic force coefficient 0.025 corresponding to 4 degree seismic region. Based on engineering geological manual (fourth edition), combined with actual situation of this project, stability safety factor of slope use 1.35 .

Calculation results in each condition are shown in Fig. 6-9. 


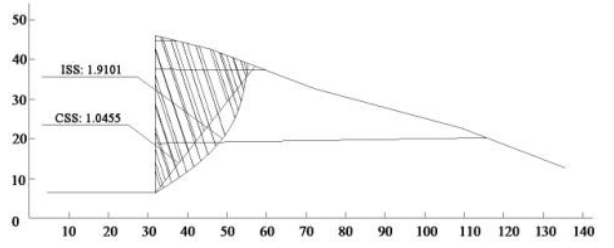

Figure 6. Calculation result in normal condition

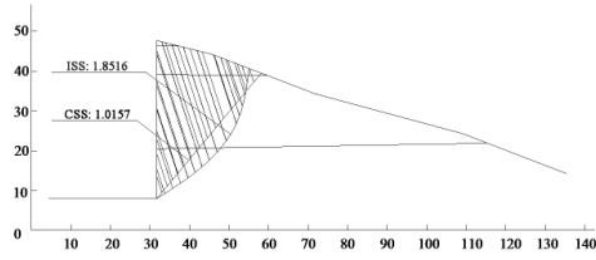

Figure 7. Calculation result in normal plus earthquake

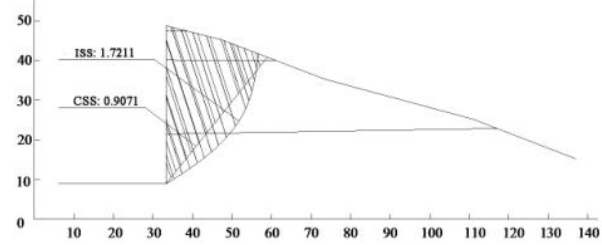

Figure 8. Calculation result in rainfall condition

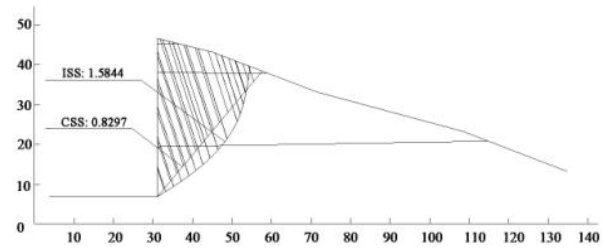

Figure 9. Calculation result in rainfall plus earthquake

Calculation results show safety factor of A-A' profile is 1.0455 in normal condition, considered earthquake, safety factor is 1.0157 . When rainfall condition, safety factor of $\mathrm{A}-\mathrm{A}^{\prime}$ profile is 0.9071 , considered earthquake, safety factor is 0.8297. Both don't meet code requirement, need take necessary engineering measures to governance slope.

Compared Fig. 3 with Fig. 6, plastic zone shown as Fig. 3 extend upward from toe of slope of excavation surface until $26.44 \mathrm{~m}$ distance to top. The critical slide plane position is shown as Fig. 6. It is have $26.36 \mathrm{~m}$ distance to the top of slope. Both agree with each well.

\section{STABILITY ANALYSIS OF SLOPE WITH ANCHOR} CABLE

In principle, in order to increase the stability of the slope, the need to improve the stability of the rock mass, increase the strength of the rock, reduce the downslide strength of the rock. Commonly artificial reinforcement methods include anti-slide pile reinforcement, retaining wall method, cable reinforcement method, etc. This project used the anchor cable reinforcement method to control slope.

Anchor reinforcement technology is anchor which is constituted by a plurality of steel strand and its accessory, through unstable landslide, anchoring into the deep stable rock mass, adjusting the stress state of rock mass, increasing the stability of rock mass. Anchor usually consists of three parts: the external anchorage segment, the tension segment and the internal anchorage segment. According to the current technology of prestressed anchor cable, the summary of the characteristics are as follows: (1) Anchor is a slender tension member, large flexibility, in the reinforcement of rock, interact with rock, to give full play to their abilities. (2) The reinforcement depth of the prestressed anchor cable can reach tens of meters, which can meet the needs of live rock reinforcement length. (3) Prestressed anchor cable reinforcement technology is a kind of active force strengthening system, control the deformation of rock mass, adjust the stress state of rock mass, and improve the stability of rock well. (4)Construction machinery of the prestressed anchor cable minimize, is convenient for field construction, short construction period, construct safety and so on. (5) The prestressed anchor cable technology makes full use of the rock strength, improves the stress state of rock, but also can combine with other structures, obtain obvious economic benefit.

The project adopts prestressed anchor reinforcement system. The length of anchor is 12 28 meters, anchor force $1500 \mathrm{KN}$, upper and lower spacing 4 meters. The safety factor of the original slip surface in the rainfall and earthquake conditions is 2.3057 after reinforcement, as shown in Fig. 10.

Fig. 11 shows the calculation results of the dangerous slip surface to the deep layer during rainfall and earthquake after reinforcement. The safety factor of dangerous slip through the end of cable is 1.6490 , meet standard requirements. Safety factor improved significantly after reinforcement.

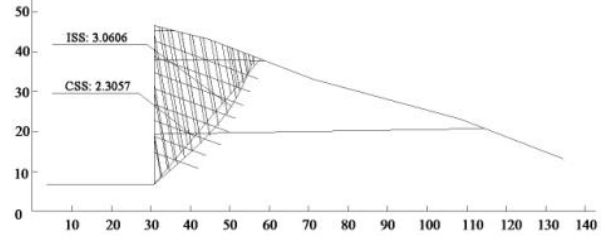

Figure 10. Calculation result in rainfall plus earthquake after reinforcement

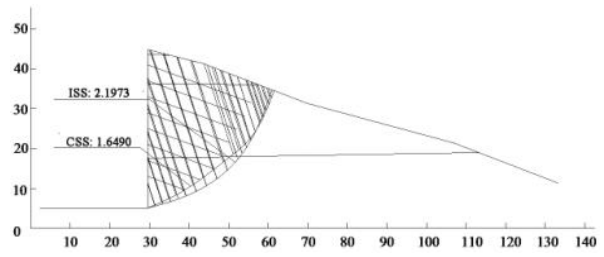

Figure 11. Deepslip surface in rainfall plus earthquake after reinforcement

\section{CONCLUSIONS}

Based on the stope in HeBei province, the sliding failure mode and treatment measure after the excavation of the stope are discussed. The RMR value was determined by the analysis to the influence of rock strength, discontinuous structure surface distance, rock quality designation, discontinuity conditions, ground water conditions of slope. Based on the formula, the shear strength parameters were obtained. The GSI value was obtained by the analysis to joint surface distance of rock or the volume and joint surface state parameters of 
rock block. Shear strength parameters were obtained, then compare of the results, and the smaller parameter is selected for the stability calculation.

The finite element numerical simulation of the slope after excavation is carried out, and the development of the displacement and plastic zone are obtained. Based on the analysis method of stiffness limit balance, the stability analysis of the slope is carried out. The calculation conditions include normal condition, normal plus rainfall, normal plus earthquake, normal plus rainfall and earthquake, the minimum safety factors corresponding four conditions are 1.0455, 1.0157, $0.9071,0.8297$ respectively, which cannot meet the standard requirement. The cable reinforcement method is used to reinforce the slope, and the minimum safety factor of the primary slope surface under the four operating conditions after strengthening is 2.3057 .
Dangerous slip surface move deep, the minimum safety factor of the dangerous slip surface through the end of the cable is 1.6490 , which meet standard requirements.

\section{REFERENCES}

[1] E. Hoek. Technical note estimating mohr-coulomb friction and cohesion values from the Hoek-Brown failure criterion. Int. J. Rock Mech Min Sci \& eomech. 1990, 27(3): 227-229.

[2] Hoek E, Brown E T. Practical estimates of rock mass strength. Int J Rock Mech Min Sci, 1998, 34(8): 1165-1 186.

[3] Michalowski R L. S1ope stability analysis: a kinematical approach. Geoteehnique, 1995, 45(2): 283-293.

[4] Institute of Rock and Soil Mechanics, Chinese Academy of Science. The Eeperimental research and computation methods for stability of the rock slope. Bei Jing: Science Press, 1981.

[5] Shao guojian,Zhuo Jiashou,Zhang Qing. Research on analysis method and criterion of rockmass stability. Chinese Journal of Rock Mechanics and Engineering, 2003, 22(5): 691-696. 